\title{
Improvement of anticorrosion coating properties in bio-based polymer epoxy acrylate incorporated with nano zinc oxide particles
}

\begin{abstract}
A new green binder of Jatropha-oil based epoxy acrylate (AEJO) resin was able to replace coatings in non-ecology-friendly technologies. The epoxy acrylate coating was blended with nano zinc oxide to make hybrid nanocomposites as a corrosion protection coating applied to a mild steel panel. AEJO was synthesized and incorporated with different loadings (1, 3, 5, 7, and 9 wt \%) of zinc oxide $(\mathrm{ZnO})$ fillers. The $\mathrm{AEJO} / \mathrm{ZnO}$ coating was applied on the mild steel substrates and characterized for corrosion protection performance by impedance spectroscopy (EIS) and salt spray tests. XRD analysis was conducted, and thermal properties by TGA were studied. The surface morphology of the hybrid coating was characterized by field emission scanning electron microscopy (FE-SEM). Incorporation of a $5 \mathrm{wt} \% \mathrm{ZnO}$ loading showed significantly enhanced corrosion resistance through EIS as well as coating performance. This study provides green-based materials and protection to surface and interface engineering.
\end{abstract}

